\title{
Estudo de tipologia documental em arquivos pessoais: contribuições para a organização do conhecimento arquivístico
}

\author{
Mabel Meira Mota ${ }^{1}$ y Francisco José Aragão Pedroza Cunha² \\ ${ }^{1}$ ORCID 0000-0003-4175-3669. Programa de Pós-graduação em Ciência da Informação, \\ Universidade Federal da Bahia, Brasil. \\ Mabelmmotagmail.com \\ ${ }^{2}$ ORCID 0000-0003-2770-7818. Programa de Pós-graduação em Ciência da Informação, \\ Universidade Federal da Bahia, Brasil. \\ pedrozaici@gmail.com
}

\begin{abstract}
Resumen. Se presenta el desarrollo y resultados parciales de la investigación de maestría desarrollada en la Línea 1 - Políticas y Tecnologías de la Información, del Programa de Postgrado en Ciencia de la Información, de la Universidad Federal de Bahía, acerca de la identificación de los tipos de documentos textuales existentes en el archivo personal de Thales de Azevedo. En el marco de la organización del conocimiento arquivístico, la identificación de tipología documental es fundamental para el desarrollo de las demás operaciones físicas e intelectuales para que se efectúa la organización de archivos, entre las cuales destacan la clasificación y la descripción. Se pretende, por lo tanto, abordar cuestiones que involucran la identificación de tipología documental en los archivos personales, evidenciando sus características en lo que se refiere a la producción documental ya la diversidad de tipologías resultantes de la praxis historiográfica emprendida por el titular. Para ello, presentamos una revisión de literatura sobre el estatuto de los archivos personales en la Archivística, y un breve histórico, conceptualización y análisis de la Identificación Documental en la literatura nacional e internacional. Por último, destacamos el papel de la identificación de tipología documental en el tratamiento de la información en los archivos personales como proceso esencial de la práctica archivística, que comporta un conjunto de actividades orientadas a posibilitar el acceso a los documentos y a la memoria en ellos registrada.
\end{abstract}

Palabras clave: Organización del conocimiento archivístico; tipología documental; archivos personales.

Abstract. The development and partial results of the master's research
developed in Line 1 - Policies and Information Technologies, of the Post-
graduate Program in Information Science, Federal University of Bahia, about
the identification of the types of textual documents in the personal archive of

Mota, M.M., Cunha, F.J.A.P. (2020). Estudo de tipologia documental em arquivos pessoais: contribuições para a organização do conhecimento arquivístico. En J. Tramullas, P. Garrido-Picazo y G. Marco-Cuenca (eds.) Actas del IV Congreso ISKO España y Portugal 2019 (pp. 137-342).

https://doi.org/10.5281/zenodo.3736639 
Thales de Azevedo. In the context of the organization of archival knowledge, the identification of documentary typology is fundamental for the development of other physical and intellectual operations in order to organize the archives, among which stand out the classification and the description. The objective is, therefore, to address issues that involve the identification of documentary typology in personal archives, evidencing its characteristics in relation to documentary production and the diversity of typologies resulting from the historiographical practice undertaken by the owner. To do so, we present a review of the literature on the status of personal archives in Archives, and a brief history, conceptualization and analysis of Documentation Identification in national and international literature. Finally, we highlight the role of identification of documentary typology in the treatment of information in personal archives as an essential process of archival practice, which includes a set of activities aimed at providing access to documents and the memory in them.

Keywords: Organization of archival knowledge; documentary typology; personal archives.

\section{Introdução}

Origem institucional e processo natural foram determinantes para delimitação do conceito de arquivo e para a disseminação de uma "matriz pública" que designou um lugar periférico para os arquivos fora dos padrões governamentais e institucionais e implicou na utilização de abordagens metodológicas distintas, de acordo com as filiações institucionais e disciplinares dos responsáveis por sua custódia (HEYMANN, 2012).

Inseridos no conjunto dos arquivos privados, os arquivos pessoais foram, e continuam sendo, em grande parte, medidos de acordo com o valor probatório e informativo, próprios aos documentos de natureza institucional, único modo de garantir-lhes uma abordagem arquivística, conforme se pode observar em Belloto (1991), a conceituação de arquivos pessoais está embutida na definição geral de arquivos privados, ao inseri-los no rol de papéis produzidos/recebidos por entidades ou pessoas físicas de direito privado. Para essa autora, não são documentos funcionais e administrativos no sentido que possuem os de gestão de organização pública ou privada, mas registros de vida familiar, civil e profissional e vinculados à produção política e/ou intelectual, científica, artística de estadistas, políticos, artistas, literatos, cientistas etc. (BELLOTO, 1991, p. 254).

A crítica pós-moderna tem demandado novos posicionamentos dos profissionais responsáveis pelo tratamento dos arquivos pessoais, considerados, agora, a partir de sua própria urdidura e especificidade. Contemporaneamente, destaca-se uma postura relativista sobre a prática arquivística, que considera o impacto da instabilidade do sujeito moderno na produção de sentidos nos arquivos (FOUCAULT, 1995). A 
observação do arquivamento proposto pelo titular do arquivo interessa, portanto, por facultar uma lógica própria para organizar os registros do que foi vivido no âmbito público e/ou no privado, conforme o uso que deles poderia ser feito. Assim, conforme Heymann (2012), "pensar os arquivos e sua produção implica, portanto, pensar em representações e práticas" (HEYMANN, 2012, p. 36).

$\mathrm{Na}$ contramão de uma vertente que enxerga e considera a "dimensão funcional" dos arquivos pessoais como preponderante no arranjo desses acervos, Catherine Hobbs afirma que "these intimate elements are reflected not only in the content and organization of personal records, but come into play in the archivist's direct interaction with the creator/donor during appraisal, acquisition, and subsequent management of personal archives" (HOBBS, 2001, p. 127). Para essa autora, se os arquivistas se concentrarem apenas na preservação do contexto transacional dos registros, vão estar valorizando-os somente pelo seu uso imediato em determinado contexto, como prova da atividade ou da finalidade para a qual ele foi criado, desconsiderando que os registros quando advindos da instância mais íntima e privada delineiam a inscrição de vários sujeitos numa mesma identidade. Nessa perspectiva, Hobbs (2001) conclui que a melhor alternativa deva ser a observação da personalidade do indivíduo que se arquiva em vez dos comportamentos condicionados socialmente.

Assim, a abordagem sugerida por Hobbs (2016) propõe que proveniência e a ordem original sejam encontradas justamente se forem observados os atos de vontade e de negligência dos produtores, se considerados os diversos elos entre os documentos da esfera pessoal e da esfera pública, se lidas as materialidades dos documentos relacionando-as a sua carga emocional e a sua utilidade prática, se entendermos que o ato de documentar e o comportamento arquivístico são derivados da condição humana em vez de limitá-los à construção de algo memorável - pois nem sempre o é -, enfim, se percebermos que "a documentação é ligada a e parte da experiência dos criadores" (HOBBS, 2012, p. 322, grifos da autora).

Os arquivos pessoais precisam, portanto, ser reintegrados à descontinuidade que lhes é inerente. Inserido no complexo e multifacetado quadro composto pelos arquivos pessoais encontram-se os documentos produzidos e acumulados por Thales de Azevedo. As peculiaridades de sua urdidura são investigadas na etapa metodológica da Identificação Arquivística, a qual torna possível a instauração de rasuras no paradigma probatório, ao afirmarem que o valor transacional é apenas um dos valores encontrados nos arquivos pessoais. Diante disso, apresenta-se o desenvolvimento e resultados parciais da pesquisa de mestrado desenvolvida na Linha 1 - Políticas e Tecnologias da Informação, do Programa de Pós-graduação em Ciência da Informação, da Universidade Federal da Bahia, acerca da identificação dos tipos de documentos textuais existentes no arquivo pessoal de Thales de Azevedo. 


\section{Metodologia de Identificação}

A terminologia "Identificação Arquivística" surge num contexto marcado, principalmente, pelo "boom da memória" decorrente de um rápido processo de mudanças que fragmentaram as paisagens identitárias, culturais, sociais, econômicas, dentre outras: a pós-modernidade. Construída na década de 1980, reflete o diálogo anterior estabelecido entre os arquivos, a História, o Direito e a Diplomática, principalmente entre os séculos XVII e XIX, que, através do estudo crítico dos elementos intrínsecos e extrínsecos dos documentos escritos, conferiam a autenticidade e fidedignidade dos fatos neles registrados. A Diplomática, ao postular conceitos e métodos para a crítica de documentos medievais, demonstrou a força de um documento escrito, que passou a ser sentida na Arquivística a partir de meados do século XX, quando Robert-Henri Bautier (1962) identifica os documentos de arquivo como o objeto de estudo da Diplomática (TOGNOLI, 2013).

A Identificação, no domínio da Arquivística, trata-se de uma investigação, de caráter intelectual, que visa recuperar a relação de indicialidade necessária entre os documentos e as funções responsáveis por sua existência. Conforme Rodrigues (2008), a metodologia de Identificação Arquivística é definida como um levantamento de dados acerca do documento de arquivo e dos vínculos que mantém com o órgão ou pessoa que o produziu, seja em fase de produção ou de acumulação. Neste sentido, é um trabalho de pesquisa e de crítica sobre a gênese documental (RODRIGUES, 2008, p. 22).

Tendo como base o Princípio da Proveniência ou Respeito aos Fundos, nessa etapa recolhem-se informações relativas a "quem?", "quando?", "como?" e, principalmente, "por quê?" os documentos foram produzidos e acumulados como registros probatórios do fazer específico de cada organização (LOPEZ, 2012), ou seja, reconhece-se a gênese documental. Rodrigues (2008), inserida no âmbito da documentação de matriz organizacional, explica que essa fase do tratamento técnico, contempla, primeiramente, o entendimento profundo do organismo produtor (evolução orgânica e competências administrativas), seguido do elemento funcional (competências, funções e atividades) e seu registro sob a forma de tipo documental (procedimento administrativo e tramitação) e, por último, a delimitação da série documental (RODRIGUES, 2008, p. 68-69).

Nesta fase também são estudados os elementos internos e externos dos documentos, que tornam possível a delimitação dos vínculos e das atividades que tornaram possível o tipo documental, para sua adequada denominação. $\mathrm{O}$ tipo documental vem a ser a "divisão da espécie documental que reúne documentos por suas características comuns no que diz respeito à fórmula diplomática, natureza de conteúdo ou técnica do registro" (DICIONÁRIO, 2005, p. 163). Conforme Bellotto (2002, p. 20), o tipo documental é "a configuração que assume uma espécie documental, de acordo com a atividade que a gerou".

$\mathrm{O}$ arquivo pessoal reflete uma justaposição de intenções, acontecimentos e práticas. Por esse motivo, tais arquivos demandam uma ampliação do aporte teórico e 
metodológico da Arquivística também no sentido de entendê-los como "evento cultural e social".

\section{Resultados}

Thales de Azevedo (1904-1995) ocupa um lugar de destaque na cena intelectual baiana e brasileira, não apenas pelo papel que desempenhou como professor e pesquisador, mas por ter explorado o ousado e o inovador na sua área de atuação, as Ciências Sociais. Voltando-se para os rituais do cotidiano, analisou a sociedade de sua época em suas regras e ritos. Considera-se, assim, o seu arquivo como uma construção inserida nos rituais do cotidiano do seu produtor, ou seja, como uma arte de fazer forjada numa prática de resistência própria ao arquivamento de si e, ao mesmo tempo, atravessada por outras subjetividades. Sendo assim, apresenta-se um breve relato sobre a experiência de aplicação da metodologia arquivística da Identificação ao arquivo pessoal dessa personalidade baiana.

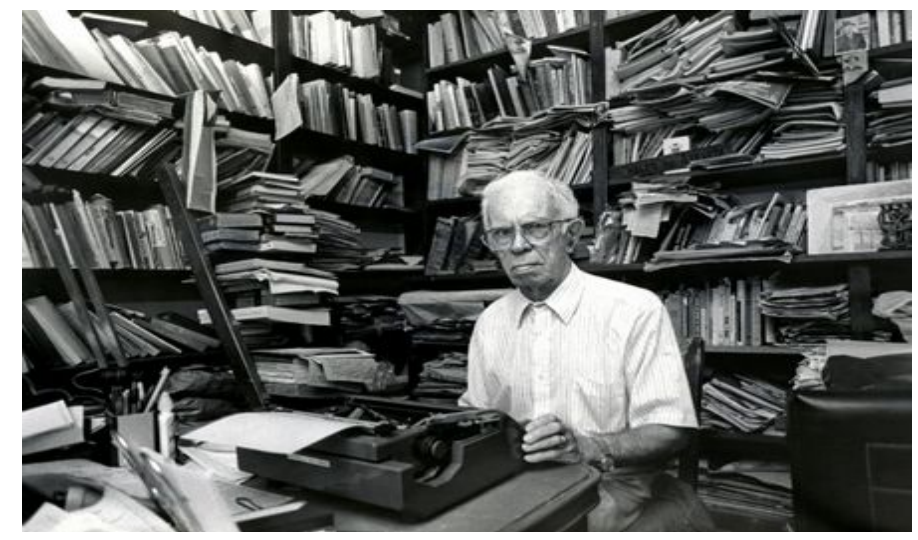

Figura 1. Thales de Azevedo em seu gabinete.

Trata-se de conjunto documental que reúne, em média, 50 mil documentos textuais, divididos entre produzidos e recebidos pelo titular; e uma biblioteca composta, atualmente, por cerca de 300 livros, de um montante anterior superior a 5 mil livros, catalogados em dois cadernos manuscritos. A biblioteca de Thales de Azevedo foi doada, em parte, pela família. Atualmente podem ser encontrados livros com o "carimbo do titular" na biblioteca do Colégio Estadual Thales de Azevedo, em Salvador; e na biblioteca da Faculdade de Filosofia e Ciências Humanas, na Universidade Federal da Bahia. No primeiro, é possível também encontrar alguns dos 21 quadros pintados por Thales de Azevedo de que temos conhecimento.

O volume de caixas, pastas, dossiês e empilhamentos, dão a ler múltiplos fragmentos biográficos. Observa-se que a multiplicidade de campos em que atuara Thales de Azevedo encontra-se representada em 52 caixas-arquivo, 40 pastas, 23 
dossiês e 12 empilhamentos, nos quais se destacam os cargos ocupados, principalmente, como presidente da ABA (Associação Brasileira de Antropologia) e também do Instituto Geográfico e Histórico da Bahia (IGHB) - do qual fora presidente em 1978 - possui maior volume nesses períodos - em torno de 8 caixasarquivo -, principalmente no que tange à correspondência passiva. Encontra-se pouco documentada, contudo, sua atuação como médico no interior da Bahia.

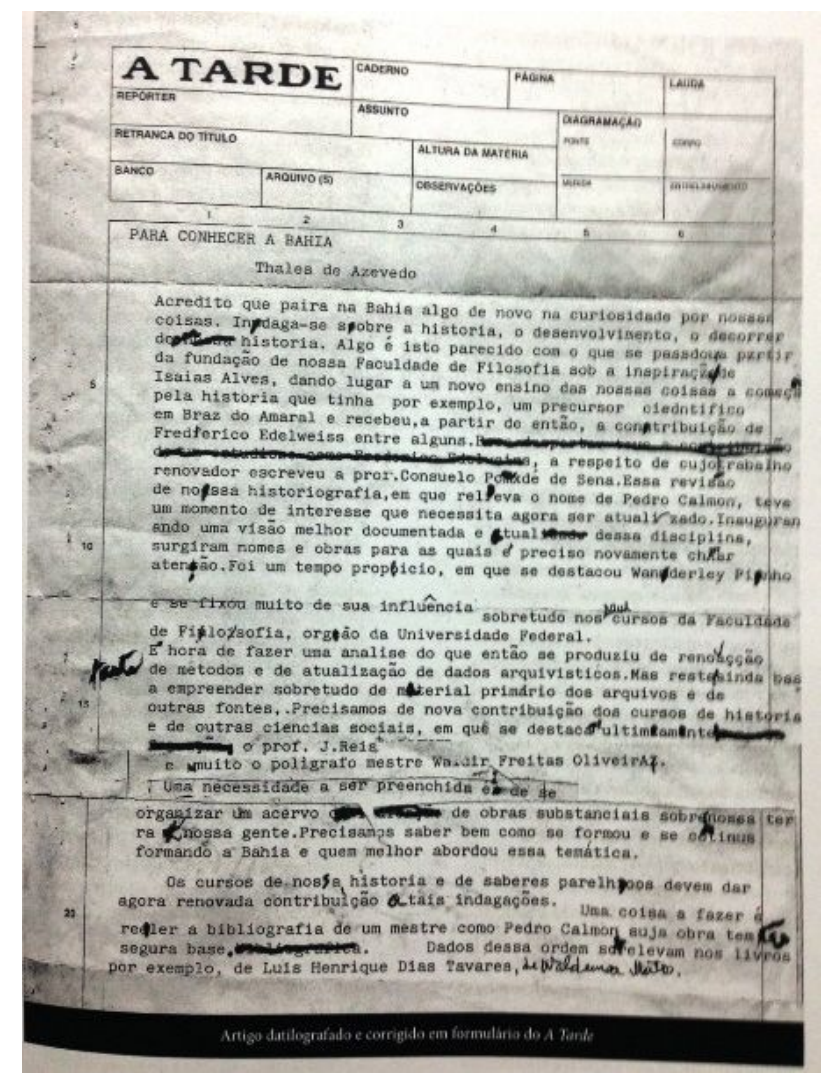

Figura 2. Produção jornalística de Thales de Azevedo (Minuta)

A dimensão privada ganha destaque pelos dossiês de pesquisa, que remetem para o exercício constante da escrita e da leitura. Há vasta correspondência com intelectuais nacionais e estrangeiros, com amigos, colegas, colaboradores e, em menor volume, com os familiares. Além disso, destaca-se a correspondência com intelectuais e docentes de Universidades Americanas de Miami, da Flórida, da Geórgia e da Califórnia. $\mathrm{O}$ arquivo inclui também uma vasta produção jornalística de Thales de Azevedo, principalmente em A Tarde (Cf. Figura 2), no qual atuara desde 1922, inicialmente como auxiliar e, posteriormente, atuando como articulista de produção semanal até a semana de sua morte. Trata-se de mais de 1400 artigos publicados, 
principalmente a partir de 1975 , quando ele passa a fazer parte do grupo de colaboradores permanentes do jornal (BRANDÃO, 1993).

Documentos de processo advindos dos diferentes ciclos de pesquisa possuem lugar de destaque no arquivo desse baiano, além de trabalhos de terceiros, enviados seja para Thales de Azevedo emitir opinião, seja para prefaciar uma publicação. Através dos primeiros é possível adentrar a dimensão privada da escritura, observando a relação entre o que pesquisador lia e escrevia, pois em alguns dos livros de sua biblioteca estão registradas anotações, marcações. Os livros lidos tornam-se, assim, dossiês (Cf. Figura 3), devido ao acréscimo de notas de leitura, de recortes e algumas análises. Fatos, versões e ficções convivem nesse arquivo.

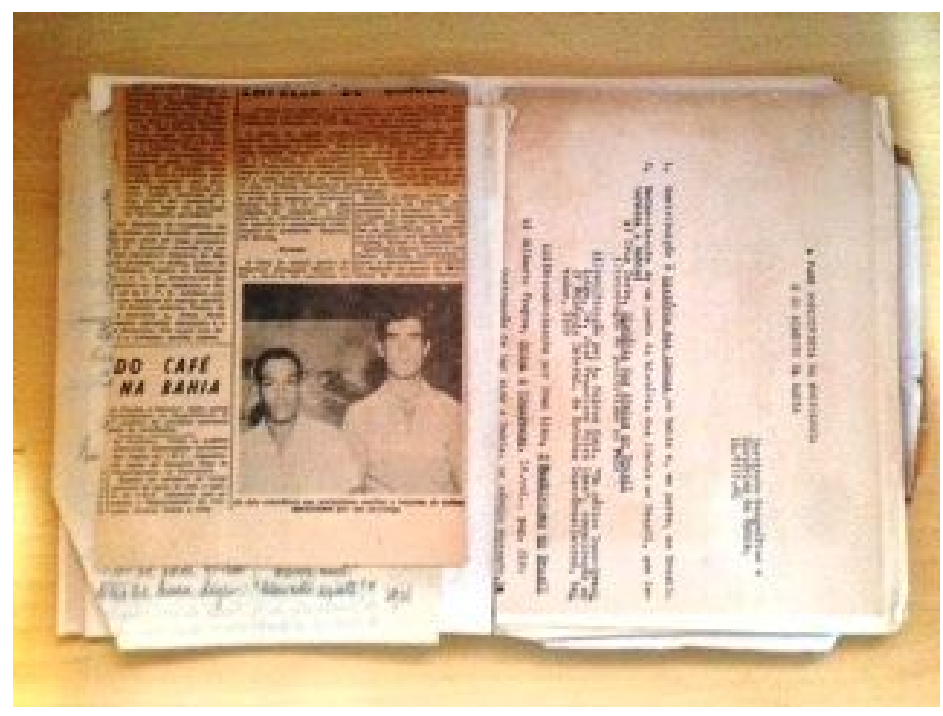

Figura 3. Livro de terceiro com marcações e anotações de Thales de Azevedo

Um volume expressivo de documentos arquivados em 29 caixas-arquivo, sem dúvida o maior, dá a ler a sistematização de uma intensa pesquisa dedicada a diversos ciclos temáticos, dos quais se destaca um conjunto de dez mil documentos - entre notas de campo, recortes de jornais e versões manuscritas de textos inéditos e daqueles publicados - referentes ao ciclo de pesquisa sobre as variações culturais inter-regionais e a migração, que remetem para diversas publicações acerca da presença de italianos no Rio Grande do Sul, das quais são expressivas as obras Gaúchos: notas de antropologia social (1943), Italianos e gaúchos: os anos pioneiros da colonização italiana no Rio Grande do Sul (1975); Os italianos no Rio Grande do Sul: cadernos de pesquisa (1994), esse último revisto e publicado um ano antes de seu falecimento; e do estudo de italianos na Bahia, expressos em Italianos na Bahia e outros temas (1989) e no conto-memória, A Filha do Alferes: nas redondezas das Guerras do Sul (1993). 
A variedade de temas pesquisados por Thales de Azevedo, para além da grande acumulação e produção documental, reflete, em geral, a coincidência temporal dos ciclos temáticos, muitas vezes estudados e documentados simultaneamente, como é o caso daquele sobre a imigração de Italianos no Rio Grande do Sul e na Bahia, e aqueles voltados para os temas do cotidiano, o ciclo da vida e seus ritos. Conforme Maria de Azevedo Bandão (2004, no prelo), num texto inédito, provável ampliação da primeira edição de Dados de uma Assinatura (1993), o cotidiano como tema de interesse de Thales de Azevedo já aparece em 1941, no primeiro ensaio sobre "O rancho de gaúchos brasileiros e uruguaios" e nas notas de uma viagem ao Uruguai, publicadas em Gaúchos (1943).

No arquivo pessoal do médico, antropólogo e professor Thales de Azevedo é possível perceber práticas ativadas em decorrência de atividades cotidianas, como é o caso da preservação dos documentos de identificação comuns e até mesmo um cartão que comunica à sociedade o seu nascimento (Cf. Figura 4), comprovantes de pagamento de contas, exames médicos, diplomas e históricos acadêmicos, dentre outros.

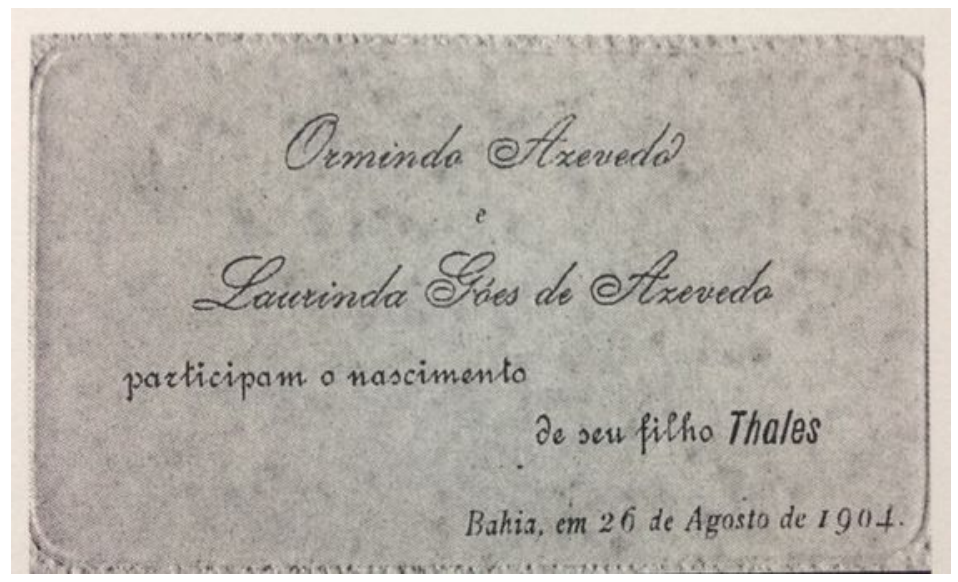

Figura 4. Cartão que comunica nascimento de Thales de Azevedo em 1904

Práticas ativadas por motivos e interesses diversos são observadas no seu arquivo, e revelam, antes de tudo, a função instrumental do arquivo para o seu produtor. Essa função instrumental pode ser lida, principalmente, pelo processo de documentação dos densos ciclos de pesquisa por ele sistematizados em torno de vários temas, como o cotidiano. Dessa tentativa de compreender as simbologias e significados próprios de práticas rotineiras, resultou um conjunto formado por: anotações de campo e de pesquisa documental, notas avulsas, folhas soltas, agendas pessoais, fotos, desenhos, listas de endereços, recortes de jornais sobre variados temas, resenhas e comentários de textos lidos, manuscritos inéditos e manuscritos de textos publicados, roteiros de aulas, seminários, apostilas, entrevistas e reportagens referentes ao tema estudado, manuscritos de terceiros, separatas recebidas de colaborados e amigos, correspondências, bibliografias e fichas bibliográficas, resumos analíticos de cada 
leitura empreendida, almanaques consultados, além de livros em cujas margens observam-se as marcas de um leitor atento.

O conjunto representativo de tais ciclos dá a ler processos de elaboração de empreendimentos intelectuais densos, nos quais não se pode estabelecer o início ou o fim, pois o tema do cotidiano ,por exemplo, no âmbito dos ciclos temáticos de pesquisa empreendidos pelo titular, perpassa diversas produções intelectuais e artísticas que suplementam umas às outras e fazem uso de dados e informações muitas vezes comuns, mas que são ressignificadas a cada retomada do tema pelo autor.

\section{Considerações finais}

A pesquisa de mestrado desenvolvida na Linha 1 - Políticas e Tecnologias da Informação, do Programa de Pós-graduação em Ciência da Informação, da Universidade Federal da Bahia, tem demonstrado que, durante a vida, as pessoas produzem documentos por razões muito diversas, nem sempre objetivando a comprovação de uma atividade, função ou cargo desempenhado. $\mathrm{O}$ arquivamento nem sempre é consciente ou voluntariamente construído para o futuro, podendo ser motivado por dar uma resposta à injunção social de comprovar o vivido; assim como pelo cultivo de emoções e experiências.

O trabalho de Identificação ainda não foi concluído, mas revela-se, desde já, importante para o futuro arranjo, descrição e difusão. Percebeu-se que para Thales de Azevedo o arquivo para além de lugar para guardar suas lembranças, tinha uma função instrumental, pois ali estava tudo que precisava para alimentar o seu ininterrupto fluxo de criativo, dado a ler em textos sempre inacabados - versões de versões -, sempre passíveis de retomadas e contínuas experimentações.

\section{Referencias}

BELLOTTO, Heloisa Liberalli.(1991). Arquivos permanentes: tratamento documental. Rio de Janeiro: Editora FGV.

BRANDÁO, Maria de Azevedo. (1993). Thales de Azevedo: dados de uma assinatura. Salvador: ABA /UFBA.

BRANDÁO, Maria de Azevedo. (2004). Thales de Azevedo: dados de uma assinatura. Salvador: UFBA. No prelo.

FOUCAULT, Michel. (1999) Nietzsche, Freud e Marx: theatrum philosoficum.Tradução Jorge Lima Barreto. São Paulo: Princípios.

HEYMANN, Luciana. Indivíduo, memória e resíduo histórico: uma reflexão sobre arquivos pessoais e o caso Filinto Müller. (1998). Estudos Históricos, 19, 41-66. 
HEYMANN, Luciana (2012). O lugar do Arquivo: a construção do legado de Darcy Ribeiro. Rio de Janeiro: Editora Contra Capa.

HOOBS, Catherine (2001). The Character of Personal Archives: Reflections on the Value of Records of Individuals. .Archivaria, 52, p.126-135.

HOOBS, Catherine. (2016). Vislumbrando o pessoal. Reconstruindo traços de vida individual (pp. 303-342).En Correntes atuais do pensamento arquivístico. Belo Horizonte: Editora UFMG.

LOPEZ, André Porto Ancona. (2003). Arquivos pessoais e as fronteiras da arquivologia. Gragoatá, Niterói, 154, p. 1-140.

RODRIGUES, Ana Célia. (2008). Diplomática contemporânea como fundamento metodológico da identificação de tipologia documental em arquivos. Tese (Doutorado em História Social) - Faculdade de Filosofia, Letras e Ciências Humanas, Universidade de São Paulo.

RODRIGUES, Ana Célia; PENHA, Noemi Andreza da. (2004). A noção de identificação arquivística na Espanha e no Brasil nas décadas de 1980-1990. Prisma.com - Revista do Centro de Estudos das Tecnologias e Ciências da Comunicação, 21, p. 1-28.

TOGNOLI, Natália Bolfarini. (2014). A construção teórica da Diplomática: em busca de uma sistematização de seus marcos teóricos como subsídio aos estudos arquivísticos. São Paulo: Editora Unesp. 